\title{
PI3K-beta Inhibitor GSK2636771
}

National Cancer Institute

\section{Source}

National Cancer Institute. PI3K-beta Inhibitor GSK2636771. NCI Thesaurus. Code

C106261.

An orally bioavailable, substituted benzimidazole inhibitor of the class I phosphoinositide 3-kinase (PI3K) beta isoform with potential antineoplastic activity. PI3K beta inhibitor GSK2636771 selectively inhibits PI3K beta kinase activity in the PI3K/Akt/mT OR pathway, which may result in tumor cell apoptosis and growth inhibition in PI3K beta-expressing and/or PTEN-driven tumor cells. Dysregulation of the PI3K/Akt/mT OR pathway is frequently found in solid tumors and results in the promotion of tumor cell growth, survival, and resistance to both chemotherapy and radiotherapy. PI3K beta is the p110beta catalytic subunit of the class I PI3K. PTEN, a tumor suppressor protein and negative regulator of PI3K activity, is often mutated in a variety of cancer cells. 